\title{
Food and nutrient intakes in young adults born preterm
}

\author{
Hanna-Maria Matinolli ${ }^{1,2}$, Satu Männistö ${ }^{1}$, Marika Sipola-Leppänen ${ }^{1,2,3}$, Marjaana Tikanmäki ${ }^{1,2}$, Kati Heinonen ${ }^{4}$, \\ Johan G. Eriksson ${ }^{1,5,6}$, Dieter Wolke ${ }^{7}$, Aulikki Lano ${ }^{8}$, Marjo-Riitta Järvelinn ${ }^{2,9}$, Marja Vääräsmäki ${ }^{1,3}$, Katri Räikkönen $^{4}$ and \\ Eero Kajantie ${ }^{1,8}$
}

BACKGROUND: Adults born preterm have higher levels of cardiometabolic risk factors than their term-born peers. Studies have suggested that at least those born smallest eat less healthily. We examined the association between early $(<34$ weeks) and late (34-36 weeks) preterm birth and diet and food preferences in adult age.

METHODS: Participants of two cohort studies located in Finland completed a validated food frequency questionnaire (FFQ) at the age of 24 years to assess their usual diet and the adherence to healthy eating guidelines by using a recommended diet index (RDI). Overall, 182 were born early preterm, 352 late preterm, and 631 were term-born controls.

RESULTS: Young women born early preterm scored 0.77 points (95\% confidence interval (Cl) $0.03,1.51$ ) lower in RDI when adjusted for sex, age, parental education, and early-life confounders, indicating a lower quality of diet. There were no differences between young women born late preterm and controls or among men. When food groups were assessed separately, men born early preterm had lower consumption of fruits and berries than controls.

CONCLUSIONS: Young women born early preterm have poorer adherence to the healthy eating guidelines than their peers born at term. Differences in diet may contribute to an increased cardiometabolic risk among adults born early preterm.

$\mathbf{P}$ reterm birth, accounting for one in nine births per year worldwide (1), has been associated with adverse health outcomes such as hypertension, type 2 diabetes, and other risk factors for adult cardiometabolic diseases (2-5). These elevated risks were first described in those born earliest or smallest, such as very preterm $(<32$ weeks of gestational age) or with very low birth weight (VLBW, $<1,500 \mathrm{~g})(5,6)$. At least some of these risks seem to extend to those born late preterm (34-36 weeks of gestational age) (7), who constitute $~ 70 \%$ of those born preterm (8). A part of these risks may be mediated through an increased overall adiposity (7) or ectopic fat (9).
Optimizing lifestyle, including dietary intake, is a way to reduce the adverse health effects of preterm birth. There is considerable evidence from experimental animal studies that food preferences are partly programmed already during fetal and early life $(10,11)$. Human studies are scarce, but in general the findings are consistent with less healthy adult diet in those exposed to fetal adversity: for instance, severe maternal undernutrition during early gestation increases the preference for fatty foods in adult age (12) and lower birth weight is associated with lower intake of vegetables and fruits (13). Studies in those born preterm are even fewer but are in line with previously mentioned studies have shown that young adults born preterm with VLBW consume markedly less fruits and berries as well as milk products than term-born peers (14). Furthermore, a recent study showed that adults born preterm had more unhealthy dietary preferences than those born at term, as assessed by the healthy eating preference index. This difference is driven by reduced appetite for protein-rich foods and wine (wine was considered healthy in that study). In that study, the quality of diet also completely mediates the association between term status and high-density lipoprotein-cholesterol (15).

We assessed dietary intake by a validated food-frequency questionnaire (FFQ) in a group of young adults born early preterm $(<34$ weeks of gestational age), late preterm (34-36 weeks of gestation), and a term-born comparison group. We examined the associations between preterm birth and macronutrient intake, an overall quality of diet and consumption of specific food items in which differences have been previously found between adults born at VLBW and controls. We hypothesized that young adults born preterm have overall less healthy diet and prefer more palatable foods, i.e., food with more pleasant or agreeable taste, instead of food considered healthy.

\section{METHODS}

\section{Participants}

The data included 1,165 participants of two Finnish cohort studies, the Ester Preterm Birth Study (7) and the Arvo Ylppö Longitudinal Study $(16,17)$. The prenatal data have been reviewed and adult data collected in a harmonized way in these cohorts, which have also

\footnotetext{
'Department of Public Health Solutions, National Institute for Health and Welfare, Helsinki, Finland; ${ }^{2}$ Institute of Health Sciences, University of Oulu, Oulu, Finland; ${ }^{3}$ PEDEGO Research Unit (Research Unit for Pediatrics, Dermatology, Clinical Genetics, Obstetrics and Gynecology), Medical Research Center Oulu (MRC Oulu), Oulu University Hospital and University of Oulu, Oulu, Finland; ${ }^{4}$ Department of Psychology and Logopedics, University of Helsinki, Helsinki, Finland; ${ }^{5}$ Department of General Practice and Primary Health Care, University of Helsinki and Helsinki University Hospital, Helsinki, Finland; ${ }^{6}$ Folkhälsan Research Center, Helsinki, Finland; ${ }^{7}$ Department of Psychology, University of Warwick, Warwick, UK; ${ }^{8}$ Children's Hospital, University of Helsinki and Helsinki University Central Hospital, Helsinki, Finland; ${ }^{9}$ Imperial College, London, UK. Correspondence: Hanna-Maria Matinolli (hanna-maria.matinolli@thl.fi)

Received 8 August 2017; accepted 8 November 2017; advance online publication 13 December 2017. doi:10.1038/pr.2017.301
} 


\section{Articles $\mid$ Mationli ie al.}

previously been used for pooled analysis to assess adult outcomes of preterm birth (17). In brief, the Ester Preterm Birth study is a cohort study of young adults assessing the effects of preterm birth on earlylife programming of adult health and disease (7). The original cohort comprised 1,980 individuals born in Northern Finland between 1985 and 1989. Of them, 987 individuals were recruited through Northern Finland Birth Cohort 1986 and the remaining 993 came from the Finnish Medical Birth Register. ESTER participants were assessed in one of the seven outreach clinics in Northern Finland. The participants were sent a letter of invitation. Shortly afterwards they were contacted by phone to give further information. Those who we were not able to contact by at least three attempts were re-invited during the 2-year study period. Similarly, participants who had not refused but those who had no time available during the outreach clinic in their area were re-contacted when the study team visited the same clinic again. In total, 753 individuals agreed to participate. Of those, 149 were born early preterm, 248 late preterm, and 356 were term-born control participants.

The Arvo Ylppö Longitudinal Study (16) is a cohort study of a source population from all deliveries in the seven maternity hospitals in the county of Uusimaa, Finland between 15 March 1985 and 14 March 1986. Of these infants, all those who were admitted to the neonatal wards of the obstetric units or transferred to the Neonatal Intensive Care Unit of the Hospital for Children and Adolescents, University of Helsinki, within 10 days of birth were included in the study $(n=1,535)$. The control infants $(n=658)$, born during the same period but not admitted to the neonatal ward, were randomly recruited from the three largest maternity hospitals in the study area. As young adults, cohort members were invited to participate in a clinical follow-up examination, into which 1,136 participated. Similar to a previous study (17), we included in the present study the 46 participants born early preterm, 129 late preterm, and further 314 term-born participants belonging to the original control group. Flowchart of the study participants is presented as Supplementary Figure $\mathbf{S 1}$ online.

Approval for the studies was obtained from the Coordinating Ethics Committee at Helsinki and Uusimaa Hospital District. Informed, written consent was obtained from all participants before any clinical examination took place.

\section{Perinatal Data}

Detailed information on maternal pregnancy has been collected from the patient records at the birth hospitals and maternal welfare clinics. According to this prospectively recorded data the gestational age of the participants (determined by ultrasonography $n=721$, based on last menstrual period $n=442$ and based on clinical decision in birth hospital $n=2$ ) was systematically confirmed when the cohort members were young adults (18). Participants were classified as born early preterm ( $<34$ full weeks of gestational age), late preterm (34-36 full weeks of gestational age), or at term ( $\geq 37$ full weeks of gestational age). The diagnoses of maternal gestational diabetes, hypertension, and pre-eclampsia were also independently verified $(19,20)$. Birthweight SD score was calculated according to Finnish birth weight standards (21) and "small for gestational age" was defined as birthweight less than 2 SD below the mean for sex and length of gestation.

\section{Clinical Examination and Questionnaires}

The participants attended a clinical examination at the mean age of 24.1 years (range 19.9-26.8 years), during which their weight and height were measured and BMI $\left(\mathrm{kg} / \mathrm{m}^{2}\right)$ calculated. Body composition (e.g., weight and body fat percentage) was measured by using segmental multifrequency bioelectrical impedance (InBody 3.0, Biospace, Seoul, Korea). Height $(\mathrm{cm})$ was measured three times with a portable stadiometer, and the mean was calculated. Participants completed questionnaires covering medical history, medications, socioeconomic status (educational attainment of the more educated parent), and lifestyle including information on smoking habits and living at parental home.

\section{Food Frequency Questionnaire}

The usual diet was assessed using the semiquantitative validated 131item food frequency questionnaire (FFQ) (22). The FFQ was designed to cover the whole diet over the preceding 12 months. The participants were asked to indicate the frequency of consumption of each food item with nine frequency categories ranging from "never or seldom" to "six or more times per day".The portion sizes were fixed separately for women and men, and when possible specified in natural units (e.g., glass, slice). The participants were asked to fill in the questionnaire at the study site, where a trained study nurse reviewed the questionnaire. Total number of forms filled in Ester study was 737 (146 early preterm, 242 late preterm, and 349 controls) and in AYLS was 465 (43 early preterm, 119 late preterm, and 303 controls). From these we excluded incompletely filled forms (e.g., total or partly empty questionnaires or the idea of the FFQ not understood; Ester $n=24$ (5 early preterm, 6 late preterm, and 13 controls), AYLS $n=4$ (1 late preterm, 3 controls)).

The average daily intakes of energy, macronutrients, and food groups were calculated by the Finnish food composition database, Fineli (National Institute for Health and Welfare) (23). Daily energy intake cutoff points of $0.5 \%$ at both ends of the daily energy intake distributions for men and women were excluded (Ester $n=7$ (two early preterm, two late preterm, and three controls), AYLS $n=2$ (two controls)). After exclusions, the sample size for the present study including participants of the Ester Preterm Birth study and participants with detailed perinatal data available from AYLS study was 1,165 , comprising 182 participants born early preterm, 352 late preterm, and 631 term-born controls.

Adherence to recommended diet. To assess the overall quality of the diet, we used the Recommended Finnish Diet Index (RDI) (24), which is based on the Finnish nutrition recommendations, published in 2005 ( (ref. 25)). The index includes eight components that represent the average daily consumption of fruits, vegetables; rye; ratio of white meat to red and processed meat; ratio of polyunsaturated fatty acids to saturated fatty acids+trans-fatty acids; salt; sucrose; and alcohol. The index score was calculated according to the quartiles of consumption of each component in control group. The overall index was formed by the sum of the points given ( 0 or 1 for alcohol and from 0 to 3 for other items). The maximum score is 24 when the intake of alcohol is included and 23 when excluded. Higher score indicates healthier diet.

For examining the consumption of specific foods in which differences have been previously found between adults born at VLBW and controls, we used the food groups calculated by combining the information on the consumption of food items.

\section{Statistical Analysis}

Statistical analysis was performed by using IBM SPSS Statistics, version 23. Demographic details were examined by $t$-test or $\chi^{2}$ analyses as appropriate. Relationships between preterm birth and food and nutrient intake in adult age were examined by linear regression analysis. Log transformations $(\ln [x+1])$ were performed for variables assessing the food intake due to non-normal data with zero values included. Therefore, the mean differences in food intake are reported as back-transformed percentages. All regression models included age and recruitment cohort (Model 1). All models assessing intakes of foods as well as RDI and its components also included total energy intake. Model 2 included, in addition to previously mentioned variables, highest parental education, maternal BMI before pregnancy, birthweight SD score, maternal smoking during pregnancy, gestational hypertension, preeclampsia, and gestational diabetes mellitus. Model 3 included, in addition to previous, current characteristics of the participant, BMI, living at parental home, and daily smoking. We rerun the analyses by replacing BMI with (i) body fat percentage and (ii) waist circumference and height. We also assessed the role of birthweight SD score and maternal hypertension during pregnancy as predictors. 
RESULTS

Characteristics of the study participants are presented in Table 1. Those born preterm were more often twins and born from a preeclamptic pregnancy. In adult life, women born early preterm had a higher body fat percentage when compared with term-born women. Further, those born preterm were living at parental home more often. An interaction between the effects of sex and preterm birth on food and nutrient intake was present in some of the outcome variables including the intake of fruits and vegetables $(P<0.001$ for both preterm groups) and the intake of meat $(P<0.01$ for early preterm and $P<0.001$ for late-preterm groups). Therefore, the results are presented separately for both sexes.

\section{Macronutrient Intakes}

The mean intakes of macronutrients in preterm and control participants are presented in Table $\mathbf{1}$, and Table 2 shows the adjusted mean differences in macronutrient intakes between these groups. Total energy intake, as well as energy intakes from carbohydrates, fat, and protein, was similar in pretermborn groups and controls. The adjustments for main confounders did not change the results. Energy from alcohol was lower in women born early preterm $(P<0.05$ in all models) when compared with term-born controls. Men born early preterm also consumed less alcohol when compared with controls, although this difference was not statistically significant. The differences remained similar when adjusted for main confounders.

\section{Adherence to Recommended Diet}

Table 3 shows the differences in the recommended diet index in preterm-born groups and term-born controls. Young women born early preterm scored 0.77 points (95\% CIs $0.03,1.51)$ lower in RDI when adjusted for sex, age, parental education, and early-life confounders (model 2), indicating a lower quality of diet. Adjustment for current mediating characteristics (model 3) attenuated the difference. When the alcohol intake was included in the total index, women born early preterm tended to score lower (mean difference -0.74 $(-1.50,0.02))$. We observed no difference in RDI score between women born late preterm and controls or in men born preterm and control men.

When the different components of the RDI were assessed separately (Supplementary Table S1), we found that the ratio of red meat to white meat was higher in women born early preterm when compared with controls. On the other hand, the alcohol consumption was lower in women born early preterm. Men born early preterm consumed less fruits and berries when compared with controls but on the other hand the ratio of red meat to white meat tended to be lower. There were no differences between the late-preterm group and controls, and we observed no differences between pretermborn groups and controls in other RDI components.

\section{Replication of Previous Findings Related to Food Items}

We assessed differences in specific food items that have been previously described between adults born at VLBW and controls (data not shown). There was a statistically significant difference in the consumption of fruits and berries between the preterm-born participants and controls so that women born early preterm consumed more and men born early preterm consumed less fruits and berries when compared with respective controls. Among men, this difference survived the adjustments for confounding factors (mean difference $-24.6 \%(-41.5,-2.9)$ in the fully adjusted model). In women the difference of $23.6 \%(0.6,51.9$; adjusted for sex, age, total energy intake, and parental education) attenuated after additional adjustments for prenatal and current lifestyle factors (mean difference 20.0\% (-3.4, 49.2)). We observed no difference between the groups in the intake of vegetables. There was no difference between the groups in the intake of milk products either. Within early-preterm women the intake was slightly higher than controls (mean difference 14.7\% $(-1.1,33.1)$ ).

Women born early preterm consumed less fat. This was seen especially in the low-fat margarines but not in the intakes of butter or oil. Within male participants born early preterm consumed more margarines, but the difference was borderline statistically significant (data not shown).

Women and men born early preterm consumed fewer sweets when compared with respective controls. This difference was seen more clearly among men and was present also in late preterm born group. In women the difference was not seen after adjustments for prenatal and current characteristics (data not shown).

\section{Additional Analyses}

We re-ran the analyses after excluding the participants born small for gestational age or from multiple pregnancies. After the exclusion of small for gestational age women, the difference in RDI between the early-preterm-born women and controls attenuated. Birthweight SD score predicted the intake of fruits and vegetables in women, such that every $1 \mathrm{SD}$ higher birthweight was associated with decreased intake of fruits and vegetables $(-6.2 \%(-11.5,-0.6))$ when adjusted for age, cohort, and parental education. Adjustments for prenatal and current characteristics attenuated the results. Maternal preeclampsia was independently associated with intake of sweets in adult age, both within men and women. Men exposed to maternal preeclampsia ate $37.0 \%(1.0,85.9)$ more sweets, whereas women exposed to maternal preeclampsia ate $-37.2 \%(18.0,52.0)$ less sweets with full adjustments.

Re-running the main analyses by replacing BMI with (i) body fat percentage (available for 553 men and 589 women) and (ii) waist circumference and height did not affect any of the results.

\section{DISCUSSION}

The purpose of this study was to assess the association between preterm birth and food and nutrient intake in young 


\section{Articles | Matinolli et al.}

Table 1. Perinatal, neonatal, and current characteristics of the young adults born preterm and their controls born at term

\begin{tabular}{|c|c|c|c|c|}
\hline \multirow[t]{2}{*}{ Characteristic } & \multicolumn{3}{|c|}{ Mean (SD)/n (\%) } & \multirow[t]{2}{*}{ Missing values } \\
\hline & $\begin{array}{c}\text { Early preterm, } \\
\mathrm{GA}<34 \text { wk }(n=182)\end{array}$ & $\begin{array}{c}\text { Late preterm, } \\
\text { GA 34-36 wk }(n=352)\end{array}$ & $\begin{array}{c}\text { Controls, } \\
\mathrm{GA} \geq 37 \text { wk }(n=631)\end{array}$ & \\
\hline Male, $n(\%)$ & $87(47.8)$ & $175(49.7)$ & $293(46.4)$ & $0 / 0 / 0$ \\
\hline Ester, $n(\%)$ & $139(76.4)^{\dagger}$ & $234(66.5)^{\dagger}$ & $333(52.8)$ & $0 / 0 / 0$ \\
\hline \multicolumn{5}{|l|}{ Pre- and neonatal } \\
\hline Multiple pregnancy, $n(\%)$ & $36(19.8)^{\dagger}$ & $47(13.4)^{\dagger}$ & $10(1.6)$ & $0 / 0 / 0$ \\
\hline Maternal gestational hypertension, $n(\%)$ & $22(12.1)$ & $46(13.1)$ & $72(11.4)$ & $4 / 15 / 25$ \\
\hline Maternal preeclampsia, $n$ (\%) & $40(22.0)^{\dagger}$ & $47(13.4)^{\dagger}$ & $20(3.2)$ & $4 / 15 / 25$ \\
\hline Maternal smoking during pregnancy, $n(\%)$ & $36(20.6)$ & $70(20.2)$ & $103(16.5)$ & \\
\hline Gestational age (wk), mean (SD) & $31.6(2.2)^{\dagger}$ & $35.8(0.8)^{\dagger}$ & $40.1(1.2)$ & $0 / 0 / 0$ \\
\hline Maternal BMI before pregnancy, mean (SD) & $22.7(3.7)^{*}$ & $22.4(3.6)$ & $22.1(3.0)$ & $9 / 6 / 13$ \\
\hline \multicolumn{5}{|l|}{ Current } \\
\hline Age at clinical examination (y), mean (SD) & $23.6(1.6)^{\dagger}$ & $23.8(1.5)^{\dagger}$ & $24.4(1.3)$ & $0 / 0 / 0$ \\
\hline \multicolumn{5}{|l|}{ BMI, mean (SD) } \\
\hline Men & $24.4(4.8)$ & $24.9(4.3)$ & $24.3(3.7)$ & $0 / 0 / 0$ \\
\hline Women & $24.1(5.1)$ & $23.2(4.1)$ & $23.4(4.3)$ & $0 / 0 / 0$ \\
\hline \multicolumn{5}{|l|}{ Percentage body fat, mean (SD) } \\
\hline Men & $18.1(7.9)$ & $18.7(7.2)^{*}$ & $17.2(5.9)$ & $0 / 0 / 2$ \\
\hline Women & $30.0(8.0)^{* *}$ & $28.1(7.1)$ & $27.6(7.6)$ & $8 / 5 / 8$ \\
\hline Upper-level tertiary & $42(23.3)$ & $93(27.0)$ & $178(28.8)$ & \\
\hline \multicolumn{5}{|l|}{ Macronutrient intake } \\
\hline Total energy intake (kcal/d) & $2,206(943)$ & $2,250(885)$ & $2,187(783)$ & $0 / 0 / 0$ \\
\hline Men & $2,585(1,083)$ & $2,537(78)$ & $2,538(854)$ & \\
\hline Women & $1,859(618)$ & $1,966(590)$ & $1,882(560)$ & \\
\hline Carbohydrate (E\%) & $46.1(6.7)$ & $46.0(6.7)$ & $45.9(6.7)$ & $0 / 0 / 0$ \\
\hline Men & $44.7(6.0)$ & $44.2(5.7)$ & $44.1(6.1)$ & \\
\hline Women & $47.4(7.0)$ & $47.7(7.1)$ & $47.2(7.0)$ & \\
\hline Fat $(E \%)$ & $33.6(5.1)$ & $33.3(5.1)$ & $33.3(5.2)$ & $0 / 0 / 0$ \\
\hline Men & $34.2(4.7)$ & $34.2(4.7)$ & $33.7(4.8)$ & \\
\hline Women & $33.1(5.3)$ & $32.4(5.3)$ & $32.9(5.5)$ & \\
\hline Protein (E\%) & $18.2(3.2)$ & $18.5(3.0)$ & $18.3(2.8)$ & $0 / 0 / 0$ \\
\hline Men & $18.7(3.6)$ & $18.9(3.0)$ & $18.7(3.0)$ & \\
\hline Women & $18.4(2.8)$ & $18.1(3.0)$ & $17.9(2.6)$ & \\
\hline Alcohol (E\%) & $1.8(2.3)^{\dagger}$ & $2.2(2.5)$ & $2.5(3.1)$ & $0 / 0 / 0$ \\
\hline Men & $2.4(2.7)^{*}$ & $2.8(2.8)$ & $3.2(3.4)$ & \\
\hline Women & $1.1(1.5)^{\dagger}$ & $1.7(2.0)$ & $1.9(2.6)$ & \\
\hline
\end{tabular}


Table 1 Continued

\begin{tabular}{|c|c|c|c|c|}
\hline \multirow[t]{2}{*}{ Characteristic } & \multicolumn{3}{|c|}{ Mean (SD)/n (\%) } & \multirow[t]{2}{*}{ Missing values } \\
\hline & $\begin{array}{c}\text { Early preterm, } \\
\mathrm{GA}<34 \text { wk }(n=182)\end{array}$ & $\begin{array}{l}\text { Late preterm, } \\
\text { GA } 34-36 \mathrm{wk}(n=352)\end{array}$ & $\begin{array}{c}\text { Controls, } \\
\mathrm{GA} \geq 37 \text { wk }(n=631)\end{array}$ & \\
\hline Recommended Diet Index & $10.2(2.8)$ & $10.5(2.8)$ & $10.5(2.0)$ & $0 / 0 / 0$ \\
\hline Men & $10.3(3.2)$ & $10.5(2.8)$ & $10.5(3.0)$ & \\
\hline Women & $10.1(2.5)$ & $10.6(2.9)$ & $10.5(2.9)$ & $0 / 0 / 0$ \\
\hline
\end{tabular}

Table 2. Linear regression models showing the mean differences (beta coefficients and $95 \% \mathrm{Cls}$ ) in intakes of macronutrients between the preterm groups and controls

\begin{tabular}{|c|c|c|c|c|c|c|c|c|}
\hline & \multicolumn{4}{|c|}{ Men } & \multicolumn{4}{|c|}{ Women } \\
\hline & \multicolumn{2}{|c|}{ Early preterm GA <34 wk } & \multicolumn{2}{|c|}{ Late preterm GA 34-36 wk } & \multicolumn{2}{|c|}{ Early preterm GA <34 wk } & \multicolumn{2}{|c|}{$\begin{array}{l}\text { Late preterm GA } 34-36 \\
\text { wk }\end{array}$} \\
\hline & $\beta$ & $95 \% \mathrm{Cl}$ & $\beta$ & $95 \% \mathrm{Cl}$ & $\beta$ & $95 \% \mathrm{Cl}$ & $\beta$ & $95 \% \mathrm{Cl}$ \\
\hline \multicolumn{9}{|c|}{ Energy (kcal/d) } \\
\hline Model $1 * *$ & -7.8 & $-243.6,227.9$ & -20.5 & $-203.1,162.2$ & -30.7 & $-172.1,110.7$ & 98.3 & $-12.5,209.2$ \\
\hline Model 2 & 18.3 & $-226.6,263.2$ & -31.4 & $-223.0,160.2$ & -65.6 & $-218.1,86.9$ & 88.7 & $-25.3,202.7$ \\
\hline \multicolumn{9}{|c|}{ Carbohydrate (E\%) } \\
\hline Model 1 & 0.3 & $-1.2,1.8$ & -0.3 & $-1.4,0.9$ & 0.2 & $-1.5,1.9$ & 0.1 & $-1.2,1.5$ \\
\hline Model 2 & 0.6 & $-1.0,2.1$ & -0.1 & $-1.3,1.1$ & -0.1 & $-1.9,1.8$ & 0.2 & $-1.2,1.5$ \\
\hline Model 1 & 0.2 & $-1.0,1.4$ & 0.5 & $-0.5,1.4$ & 0.1 & $-1.2,1.5$ & -0.2 & $-1.3,0.8$ \\
\hline Model 2 & 0.4 & $-0.8,1.7$ & 0.5 & $-0.4,1.5$ & 0.4 & $-1.0,1.8$ & -0.2 & $-1.3,0.9$ \\
\hline Model 3 & 0.4 & $-0.8,1.7$ & 0.5 & $-0.5,1.5$ & 0.4 & $-1.1,1.8$ & -0.2 & $-1.2,0.9$ \\
\hline \multicolumn{9}{|l|}{ Protein (E\%) } \\
\hline Model 1 & -0.1 & $-0.9,0.7$ & 0.1 & $-0.5,0.7$ & 0.4 & $-0.3,1.1$ & 0.3 & $-0.2,0.8$ \\
\hline Model 2 & -0.2 & $-1.0,0.6$ & 0.1 & $-0.6,0.7$ & 0.5 & $-0.2,1.2$ & 0.3 & $-0.3,0.8$ \\
\hline Model 3 & -0.3 & $-1.1,0.5$ & 0.0 & $-0.6,0.6$ & 0.5 & $-0.2,1.2$ & 0.3 & $-0.2,0.8$ \\
\hline
\end{tabular}

$\mathrm{GA}$, gestational age; $\mathrm{Cl}$, confidence interval; E\%, percent of total energy intake.

${ }^{*} P$ value $<0.01$.

${ }^{* *}$ Adjusted models are:

Model 1: adjusted for age and cohort.

Model 2: adjusted in addition for parental education, birth weight SD score, maternal BMI before pregnancy, maternal smoking, and maternal pregnancy disorders.

Model 3: adjusted in addition for BMl, smoking, and living at parental home.

adult age. We hypothesized that young adults born preterm have an overall less healthy diet and prefer more palatable foods rather than foods considered healthy. We found partial support for this hypothesis. Although there was no difference in macronutrient intake, women born preterm had a $0.25 \mathrm{SD}$ lower RDI than women born at term, when perinatal characteristics including the etiology of preterm birth were accounted for. This indicates poorer adherence to nutritional 


\section{Articles $\mid$ Mationoli ie al.}

Table 3. Linear regression models showing the differences ( $95 \% \mathrm{Cls}$ ) in recommended diet index in the preterm groups and controls

\begin{tabular}{|c|c|c|c|c|c|c|c|c|c|c|}
\hline & \multicolumn{5}{|c|}{ Men } & \multicolumn{5}{|c|}{ Women } \\
\hline & \multirow{2}{*}{$\frac{\text { Controls }}{\text { Mean (SD) }}$} & \multicolumn{2}{|c|}{$\begin{array}{l}\text { Early preterm, } \\
\mathrm{GA}<34 \text { wk }\end{array}$} & \multicolumn{2}{|c|}{$\begin{array}{l}\text { Late preterm, GA 34- } \\
\qquad 36 \mathrm{wk}\end{array}$} & \multirow{2}{*}{$\frac{\text { Controls }}{\text { Mean (SD) }}$} & \multicolumn{2}{|c|}{$\begin{array}{c}\text { Early preterm, } \mathrm{GA}<34 \\
\text { wk }\end{array}$} & \multicolumn{2}{|c|}{$\begin{array}{l}\text { Late preterm, GA 34- } \\
36 \mathrm{wk}\end{array}$} \\
\hline & & $\beta$ & $95 \% \mathrm{Cl}$ & $\beta$ & $95 \% \mathrm{Cl}$ & & $\beta$ & $95 \% \mathrm{Cl}$ & $\beta$ & $95 \% \mathrm{Cl}$ \\
\hline Recommended & 10.5 & & & & & 10.5 & & & & \\
\hline Diet Index ${ }^{a}$ & $(3.0)$ & & & & & $(2.9)$ & & & & \\
\hline Model $1^{\mathrm{b}}$ & & -0.28 & $-1.03,0.47$ & -0.04 & $-0.62,0.54$ & & -0.55 & $-1.24,0.14$ & 0.06 & $-0.48,0.60$ \\
\hline Model 2 & & -0.36 & $-1.14,0.42$ & -0.08 & $-0.69,0.53$ & & -0.77 & $-1.51,-0.03^{*}$ & -0.01 & $-0.57,0.54$ \\
\hline Model 3 & & -0.37 & $-1.15,0.40$ & -0.01 & $-0.62,0.60$ & & -0.67 & $-1.40,0.07$ & 0.04 & $-0.52,0.59$ \\
\hline
\end{tabular}

recommendations. Much of this difference were because of higher ratio of red to white meat. Men born early preterm consumed less fruits and berries, consistent with previous studies $(13,14)$, although their overall RDI was similar to men born at term. Interestingly, some differences were opposite among women and men. Women born early preterm had a higher intake of fruits and berries when compared with termborn women and men born early preterm tended to have lower ratio of red meat to white meat in their diets than controls. Against our hypothesis, the overall consumption of more palatable foods, i.e., those rich in sugar or fats did not differ between the groups. If anything, the intake of sweets and fats was rather lower in early-preterm-born men when compared with controls. Neither did we observe any difference in the consumption of milk products between the preterm-born groups and controls.

In a study that assessed the food and nutrient intakes by 3 day food records, young adults born preterm at $<1,500 \mathrm{~g}$ ate less fruits and vegetables and used less milk products compared with healthy term-born controls (14). Corresponding results were reported from a study that assessed the association between birthweight and food and nutrient intake in older age in which lower birthweight was associated with lower intake of fruits and vegetables (13). These dietary habits are consistently linked with higher risk for cardiovascular diseases $(26,27)$, a risk that has been repeatedly found in the preterm-born group when compared with controls $(4,5,7)$. In our study, early-preterm-born men consumed markedly less fruits and berries when compared with control participants, which may further increase their risk for cardiovascular diseases even though there is no difference in the overall healthiness of their diet when compared with term-born controls. As previously reported, young adults born early preterm in Ester cohort have higher body fat percentages, waist circumferences, and blood pressure when compared with term-born peers (7). They also have lower muscular fitness (28). Diet and exercise are potential ways for reducing the risks these individuals have.
We assessed the adherence to the recommended Finnish diet by using a predefined dietary index. Recent findings have shown that a diet following the Finnish nutrition recommendations helps in preventing overweight and obesity (24). Although the index used does not take into account all dietary components, it provides a useful tool for assessing the healthiness of diet. We found that young women born early preterm have lower adherence to recommended healthy diet and possibly more unhealthy overall dietary habits. This finding is consistent with a recent study that found that young adults born preterm had less healthy dietary preferences than controls, as assessed by a healthy eating preference index (15). That study, as well as other recent studies, did not report findings separately in women and men. Sex-specific differences have been reported previously (29) and, as dietary habits often are different between sexes even within age groups and socioeconomic groups (30), it is reasonable to run the analyses for both sexes separately.

Potential biological mechanisms linking preterm birth to later food intake are unknown, but may be related to changes in peripheral signaling and hypothalamic homeostatic regulation (10). Animal models have shown that dietary restrictions during pregnancy are associated with decreased leptin and increased ghrelin levels, thus inducing hyperphagia (31). In human studies the results are still few, but it has been shown that fetal growth restriction alters the hedonic response already at birth (32) and may thus lead to altered food preferences later in life. Understanding these factors might provide opportunities in early prevention of the cardiometabolic risks related to preterm birth.

One of the most consistent findings in studies concerning the young adult health and lifestyle of those born preterm is that they consume less alcohol when compared with termborn peers (33-35). Our findings are in line with these studies. Alcohol consumption has a major impact on overall health (36), and thus the lower intake of alcohol in preterm born adults may protect them from otherwise increased health risks, including less healthy diet. 
The main strengths of this study include a relatively large early and late preterm and control groups recruited from geographically defined catchment areas. The study design has enabled us to assess the food and nutrient intake across the full range of preterm birth. However, as the population of the study is drawn from population, there is always a chance of findings arising by chance. We have been able to take in account a wide range of confounding factors, although the risk of residual confounding still remains a possibility. As previously reported (37), those born preterm live at their parents' home longer, which may improve their dietary choices. This was adjusted for in the analyses.

A possible limitation of our study is participation bias. Previously published non-participant analyses have not raised such concern though $(7,17)$. The study designs of the original cohorts differ; thus, the proportions of preterm and termborn participants varies. To take this difference into account, all analyses were adjusted for the recruitment cohort. To assess the average food intake we used a widely validated measure, which is practical in data collection and easy for participants to complete. Although diet records are more accurate in assessing the food consumed, FFQ provides a more useful tool for assessing the long-term diet as the dayto-day variation in nutrient intake is large. It should be noted, however, that we used a self-applied form that can bring along bias due to misreporting. Our forms were checked by a trained study nurse, and missing items and clear errors in reporting were corrected. The intakes of sweets and alcohol are prone to under-reporting, whereas the intakes of fruits and vegetables are often over-reported. In order to take account of this, we adjusted the analyses for total energy intake. It has been shown that maternal diet and childhood diet/dietary habits have a role in programming of dietary preferences. Unfortunately, we were not able to assess these factors in the current study.

In conclusion, the total energy intake, as well as energy intakes from carbohydrates, fat, and protein was similar in preterm-born groups and controls. However, we found that young women born early preterm have slightly less healthy diet when compared with term-born peers. Men born early preterm also showed unhealthier intake of some food items. Differences in diet may in part contribute to increased cardiometabolic risk among adults born early preterm.

\section{SUPPLEMENTARY MATERIAL}

Supplementary material is linked to the online version of the paper at http://www.nature.com/pr

\section{STATEMENT OF FINANCIAL SUPPORT}

The ESTER study was supported by grants from the Academy of Finland (SALVE program for 2009-2012 and grants 127437, 129306, 130326, 134791, and 263924 (to E.K.)), the Emil Aaltonen Foundation, European Commission (Framework 5 award QLG1-CT-2000-001643 (to M.R.J.)), the Finnish Foundation for Pediatric Research, the Finnish Government Special Subsidiary for Health Sciences (evo), Finnish Medical Society: Duodecim, the Jalmari and Rauha Ahokas Foundation, the Juho Vainio Foundation, the Novo Nordisk Foundation, the Signe and Ane Gyllenberg Foundation, the Sigrid Jusélius Foundation, the Jenny and Antti Wihuri Foundation, and the Yrjö Jahnsson Foundation. In addition, NFBC1986 received financial support from the Academy of Finland (grants 175617, 173454, 24300269, and 24300217); EU FP7-ENV-2008-1-226534; USA/NIH/NHLBI 1-R01HL087679-01; RFP-RM-06-008; NorFA (50847); Thule Institute (50925); Oulu University Hospital, Oulu, Finland (24301140); and University of Oulu, Finland (24000692 and 24500283). The AYLS Study childhood follow-up was financially supported by the Bundesministerium für Forschung und Technik (Federal Goverment of Germany, Ministry of Science and Technology) program grants PKE 4 and JUG 14 (FKZ's 0706224, 0706564, and 01EP9504) to Klaus Riegel, Dieter Wolke, and Barbara Ohrt. Adulthood follow-up was financially supported by the Academy of Finland program grants (to J.G.E., K.R., and E.K.). The work by Aulikki Lano was supported by Foundation of Pediatric Research. The work by Heinonen and J. Lahti was supported by Academy of Finland post-doctoral grant. Eriksson was supported also by grant from Samfundet Folkhälsan and Andersson from Päivikki and Sakari Sohlberg Foundation and Finska Läkaresällskapet.

\section{DISCLAIMER}

The funders had no role in the conduct of the study or preparation of the manuscript.

Disclosure: The authors declare no conflict of interest.

\section{REFERENCES}

1. Blencowe H, Cousens S, Oestergaard MZ, et al. National, regional, and worldwide estimates of preterm birth rates in the year 2010 with time trends since 1990 for selected countries: a systematic analysis and implications. Lancet 2012;379:2162-72.

2. Kajantie E, Strang-Karlsson S, Hovi P, et al. Insulin sensitivity and secretory response in adults born preterm: the Helsinki Study of Very Low Birth Weight Adults. J Clin Endocrinol Metab 2015;100:244-50.

3. Tinnion R, Gillone J, Cheetham T, Embleton N. Preterm birth and subsequent insulin sensitivity: a systematic review. Arch Dis Child 2014;99:362-8.

4. Li S, Xi B. Preterm birth is associated with risk of essential hypertension in later life. Int J Cardiol 2014;172:e361-3.

5. de Jong F, Monuteaux MC, van Elburg RM, Gillman MW, Belfort MB. Systematic review and meta-analysis of preterm birth and later systolic blood pressure. Hypertension 2012;59:226-34.

6. Hovi P, Andersson S, Eriksson JG, et al. Glucose regulation in young adults with very low birth weight. N Engl J Med 2007;356:2053-63.

7. Sipola-Leppanen M, Vaarasmaki M, Tikanmaki M, et al. Cardiometabolic risk factors in young adults who were born preterm. Am J Epidemiol 2015;181:861-73.

8. Martin JA, Osterman MJ. Preterm births-United States, 2006 and 2010. MMWR Surveill Summ 2013;62:136-8.

9. Thomas EL, Parkinson JR, Hyde MJ, et al. Aberrant adiposity and ectopic lipid deposition characterize the adult phenotype of the preterm infant. Pediatr Res 2011;70:507-12.

10. Portella AK, Kajantie E, Hovi P, et al. Effects of in utero conditions on adult feeding preferences. J Dev Orig Health Dis 2012;3:140-52.

11. Silveira PP.. Playing with food: the fetal programming of food preferences. Obesity 2014;22:1210.

12. Lussana F, Painter RC, Ocke MC, Buller HR, Bossuyt PM, Roseboom TJ. Prenatal exposure to the Dutch famine is associated with a preference for fatty foods and a more atherogenic lipid profile. Am J Clin Nutr 2008;88: $1648-52$.

13. Perala MM, Mannisto S, Kaartinen NE, et al. Body size at birth is associated with food and nutrient intake in adulthood. PLoS ONE 2012;7: e46139.

14. Kaseva N, Wehkalampi K, Hemio K, et al. Diet and nutrient intake in young adults born preterm at very low birth weight. J Pediatr 2013;163: $43-8$.

15. Sharafi M, Duffy VB, Miller RJ, Winchester SB, Huedo-Medina TB, Sullivan MC. Dietary behaviors of adults born prematurely may explain future risk for cardiovascular disease. Appetite 2016;99:157-67. 


\section{Articles | Matinolli et al.}

16. Heinonen K, Räikkönen K, Pesonen AK, et al. Prenatal and postnatal growth and cognitive abilities at 56 months of age: a longitudinal study of infants born at term. Pediatrics 2008;121:1325-33.

17. Matinolli HM, Männistö S, Sipola-Leppänen M, et al. Body image and eating behavior in young adults born preterm. Int J Eat Disord 2016;49:572-80.

18. Sipola-Leppanen $M$, Vääräsmäki M, Tikanmäki M, et al. Cardiovascular risk factors in adolescents born preterm. Pediatrics 2014;134:1072-81.

19. Miettola S, Hartikainen AL, Vaarasmaki M, et al. Offspring's blood pressure and metabolic phenotype after exposure to gestational hypertension in utero. Eur J Epidemiol 2013;28:87-98.

20. Vaarasmaki M, Pouta A, Elliot P, et al. Adolescent manifestations of metabolic syndrome among children born to women with gestational diabetes in a general-population birth cohort. Am J Epidemiol 2009;169:1209-5.

21. Pihkala J, Hakala T, Voutilainen P, Raivio K. Characteristic of recent fetal growth curves in Finland [in Finnish]. Duodecim 1989;105:1540-6.

22. Mannisto S, Virtanen M, Mikkonen T, Pietinen P. Reproducibility and validity of a food frequency questionnaire in a case-control study on breast cancer. J Clin Epidemiol 1996;49:401-9.

23. Reinivuo H, Hirvonen T, Ovaskainen ML, Korhonen T, Valsta LM. Dietary survey methodology of FINDIET 2007 with a risk assessment perspective. Public Health Nutr 2010;13:915-9.

24. Kanerva N, Kaartinen NE, Ovaskainen ML, Konttinen H, Kontto J, Mannisto S. A diet following Finnish nutrition recommendations does not contribute to the current epidemic of obesity. Public Health Nutr 2013;16:786-94.

25. National Nutrition Council National Nutrition Council. Finnish Nutrition Recommendations, 2005 (http://www.ravitsemusneuvottelukunta.fi/portal/ en/nutrition_recommendations/). Accessed February 2016.

26. Joshipura KJ, Hu FB, Manson JE, et al. The effect of fruit and vegetable intake on risk for coronary heart disease. Ann Intern Med 2001;134:1106-4.

27. Rissanen TH, Voutilainen S, Virtanen JK, et al. Low intake of fruits, berries and vegetables is associated with excess mortality in men: the
Kuopio Ischaemic Heart Disease Risk Factor (KIHD) Study. J Nutr 2003;133:199-204.

28. Tikanmäki M, Tammelin T, Sipola-Leppänen $M$, et al. Physical fitness in young adults born preterm. Pediatrics 2016;137:1-10.

29. Barbieri MA, Portella AK, Silveira PP, et al. Severe intrauterine growth restriction is associated with higher spontaneous carbohydrate intake in young women. Pediatr Res 2009;65:215-0.

30. Helldán A, Raulio S, Kosola M, Tapanainen H, Ovaskainen ML, Virtanen S. Finravinto 2012 -Tutkimus - The National FINDIET 2012 Survey 16. Helsinki, Finland: THL, 2013.

31. Desai M, Gayle D, Babu J, Ross MG. Programmed obesity in intrauterine growth-restricted newborns: modulation by newborn nutrition. Am J Physiol Regul Integr Comp Physiol 2004;288:R91-6.

32. Ayres C, Agranonik M, Portella AK, Filion F, Johnston CC, Silveira PP. Intrauterine growth restriction and the fetal programming of the hedonic response to sweet taste in newborn infants. Int J Pediatr 2012;2012: 657379.

33. Hack M, Flannery DJ, Schluchter M, Cartar L, Borawski E, Klein N. Outcomes in young adulthood for very-low-birth-weight infants. N Engl J Med 2002;346:149-57.

34. Cooke RW. Health, lifestyle, and quality of life for young adults born very preterm. Arch Dis Child 2004;89:201-6.

35. Husby IM, Stray KM, Olsen A, et al. Long-term follow-up of mental health, health-related quality of life and associations with motor skills in young adults born preterm with very low birth weight. Health Qual Life Outcomes 2016;14:56 016-0458-y.

36. Smyth A, Teo KK, Rangarajan S, et al. Alcohol consumption and cardiovascular disease, cancer, injury, admission to hospital, and mortality: a prospective cohort study. Lancet 2015;386:1945-54.

37. Mannisto T, Vaarasmaki M, Sipola-Leppanen M, et al. Independent living and romantic relations among young adults born preterm. Pediatrics 2015;135:290-7. 